Eine Nahrungsmittelkontrolle, die sich bei der Untersuchung von Eierteigwaren lediglich darauf beschränkt, auf die Anwesenheit künstlicher Färbung zu fahnden und jede nicht deklarierte Färbung schlechtbin ohne die begleitenden Nebenumstände, die sich u. a. aus der sonstigen Zusammensetzung ergeben, zu bexücksichtigen, als „Fälschung" ansieht, hat den Vorteil denkbar grölter Einfachheit für sich; das Recht jedoch, als sachgemäß anerkinnt zu werden, vermag ich ihr nicht zuzugestehen.

Tch beabsichtige bei Streifung der Färbungsfrage keinerlei Konzessionen nach dieser Richtung zu machen, sondern wollte nur darauf hinweisen, daß Fälle vorkommen können, die nicht in den Rahmen einer schematischen Beurteilung fallen, bei denen vielmehr anter Umständen eine abweichende Auffassung Platz greifen kann.

\title{
Zur Bestimmung des Nikotins.
}

$$
\text { Von }
$$

Julius Tóth in Budapest.

J. J. Pontag ${ }^{1}$ ) hat sich vor kurzem über mein Nikotin-Bestimmungs-Verfahren ungünstig geäuBert, obne seine Behauptung mit Untersuchungsergebnissen näher begründet zu haben. Seit der Veröffentlichung meines Verfabrens ${ }^{2}$ ) ist Pon tag der erste, der dieselbe einer kurzen Kritk unterwirft.

Ich weiß nicht, ob sich andere Forscher bemüht haben, mein Verfahren in die Praxis einzuführen und welche Erfahrungen sie bei ihren Versuchen gesammelt haben, jedoch kann ich die Kritik Pontag's nicht ohne Bemerkung vorübergehen lassen. Sowohl vor der Veröffentlichung meines Verfahrens als auch nachher babe ich mehrere Parallel-Bestimmungen angeführt, welche immer die Verwendbarkeit meines Verfahrens bewiesen haben, wovon einige Beispiele hier Platz finden mögen.

Die vergleichenden Bestimmungen nach dem Kißling'schen und meinem Verfahren ergaben:

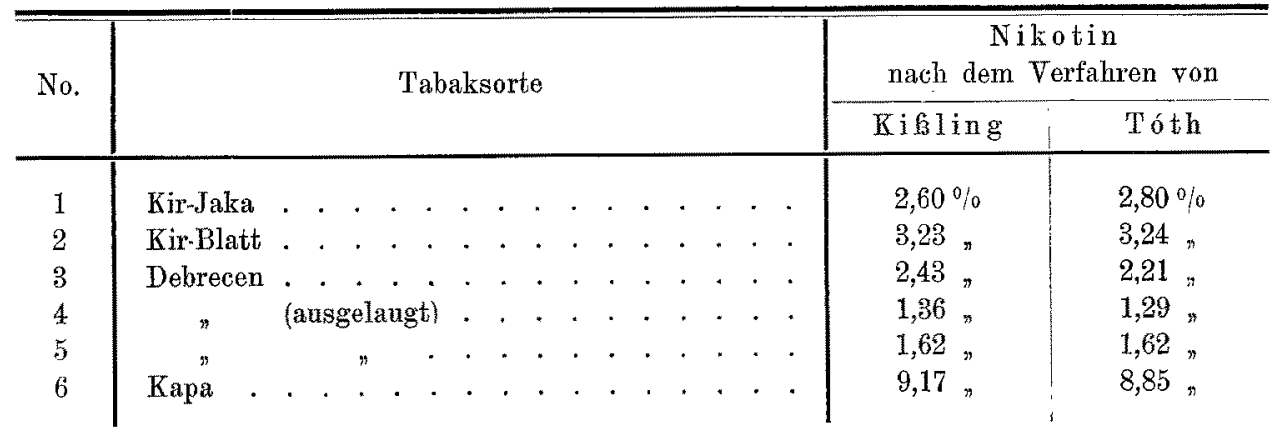

Wie aus dieser Tabelle ersichtlich ist, sind die Ergebnisse der Bestimmungen nach beiden Verlahren als sehr gut übereinstimmend zu bezeichnen.

Ich muß daher Pontag's Behauptung entschieden zurückweisen und weiterhin auf meinem bisherigen Standpunkt bezüglich der Brauchbarkeit meines Verfahrens stehen bleiben.

1) Diese Zeitschrift $1908,6,637$.

2) Revue international des falsifications 1901, 14, 12; auch Chem.-Ztg. 1901, 20̃, 610; diese Zeitschrift 1901, 4, 1041. 